\title{
X-Chromosome Kiss and Tell: How the Xs Go Their Separate Ways
}

\author{
M.C. Anguera, B.K. Sun, N. Xu, And J.T. LeE \\ Howard Hughes Medical Institute, Department of Molecular Biology, Massachusetts General Hospital, \\ Department of Genetics, Harvard Medical School, Boston, Massachusetts 02114
}

\begin{abstract}
Loci associated with noncoding RNAs have important roles in X-chromosome inactivation (XCI), the dosage compensation mechanism by which one of two X chromosomes in female cells becomes transcriptionally silenced. The Xs start out as epigenetically equivalent chromosomes, but XCI requires a cell to treat two identical X chromosomes in completely different ways: One X chromosome must remain transcriptionally active while the other becomes repressed. In the embryo of eutherian mammals, the choice to inactivate the maternal or paternal $\mathrm{X}$ chromosome is random. The fact that the Xs always adopt opposite fates hints at the existence of a trans-sensing mechanism to ensure the mutually exclusive silencing of one of the two Xs. This paper highlights recent evidence supporting a model for mutually exclusive choice that involves homologous chromosome pairing and the placement of asymmetric chromatin marks on the two Xs.
\end{abstract}

\section{NONCODING RNAS OF THE X-INACTIVATION CENTER}

$\mathrm{XCI}$ is the transcriptional silencing of one $\mathrm{X}$ chromosome in female cells in order to equalize the dosage of X-linked genes between males (XY) and females (XX) (Lyon 1961). There are two lineage-specific forms of XCI, referred to as "imprinted" and "random" XCI (Boumil and Lee 2001; Heard 2005; Lucchesi et al. 2005). The imprinted form of XCI occurs in extraembryonic tissues of eutherians and is characterized by exclusive silencing of the paternal X (Huynh and Lee 2001; Takagi and Sasaki 1975). Random XCI-where both Xs have an equal chance of undergoing inactivation-is a multistep process that occurs in the embryo proper (Avner and Heard 2001; Cohen and Lee 2002; Clerc and Avner 2003; Heard 2004). These phases have been defined genetically and consist of counting, choice, establishment of silencing, and maintenance of silencing. The counting mechanism determines the $\mathrm{X}$-to-autosome ratio and inactivates one $\mathrm{X}$ chromosome per diploid nucleus. This is followed by a choice step where the Xs are designated to become active and inactive $\mathrm{Xs}$ ( $\mathrm{Xa}$ and $\mathrm{Xi}$, respectively). Transcriptional silencing of $\mathrm{Xi}$ begins during the establishment phase and is propagated along the chromosome. Finally, the silent $\mathrm{Xi}$ is preserved in new cell populations during the maintenance phase.

Both random and imprinted XCI require the Xinactivation center $(X i c)$, an X-linked domain that contains a number of noncoding RNA (ncRNA) genes important for XCI (shown in Fig. 1) (Plath et al. 2002; Willard and Carrel 2001). The Xist gene (X-inactive specific transcript) encodes a $17-\mathrm{kb}$ alternatively spliced ncRNA that accumulates in cis along the $\mathrm{X}$ chromosome designated for silencing (Borsani et al. 1991; Brockdorff et al. 1991, 1992; Brown et al. 1991, 1992; Clemson et al. 1996). This noncoding locus is essential for the silencing step (Penny et al. 1996; Marahrens et al. 1997). Xist expression is regulated with the help of its noncoding antisense partner,
Tsix (Lee et al. 1999a; Lee and Lu 1999; Sado et al. 2001). The transcription of Tsix inhibits Xist expression in cis, effectively blocking silencing on the future Xa (Luikenhuis et al. 2001; Morey et al. 2001; Sado et al. 2001; Stavropoulos et al. 2001; Lee 2002a). Tsix expression is regulated by another locus that makes the ncRNA called Xite, located upstream of the major Tsix transcriptional start site. Xite functions in part as an enhancer of Tsix to ensure the persistence of Tsix expression during cellular differentiation (Ogawa and Lee 2003; Stavropoulos et al. 2005). In short, Xist silences the future Xi, whereas Tsix and Xite together designate the future Xa.

\section{X-CHROMOSOME INACTIVATION: TWO IDENTICAL SUBSTRATES, TWO OPPOSITE OUTCOMES}

Recent models suggest that these noncoding genes work together to mediate counting and choice and determine the pattern of X-inactivation in a cell-autonomous fashion. The process of XCI requires a cell to act oppositely upon two epigenetically equivalent chromosomes: As one $\mathrm{X}$ persists as a transcriptionally active chromosome, the other becomes globally silent. In the embryo of eutherian mammals, the choice to inactivate the maternal or paternal $\mathrm{X}$ is random and invariably takes place in a mutually exclusive manner. The precision with which choice is determined implies the existence of a cross-talking process or a feedback mechanism to guarantee the distinct fates of the two Xs. The loss of mutual exclusion in homozygous Tsix knockout mice has provided the first experimental evidence for the idea of trans-sensing (Lee 2002a, 2005).

Conceptually, mutually exclusive fates of the X chromosomes could be achieved in several ways (Fig. 2). One possibility is that the two $\mathrm{X}$ chromosomes are not really equivalent at the beginning of XCI (Fig. 2A), a possibility congruent with the imprinted status of the Xs in extraembryonic cells in which the stereotypical paternal 


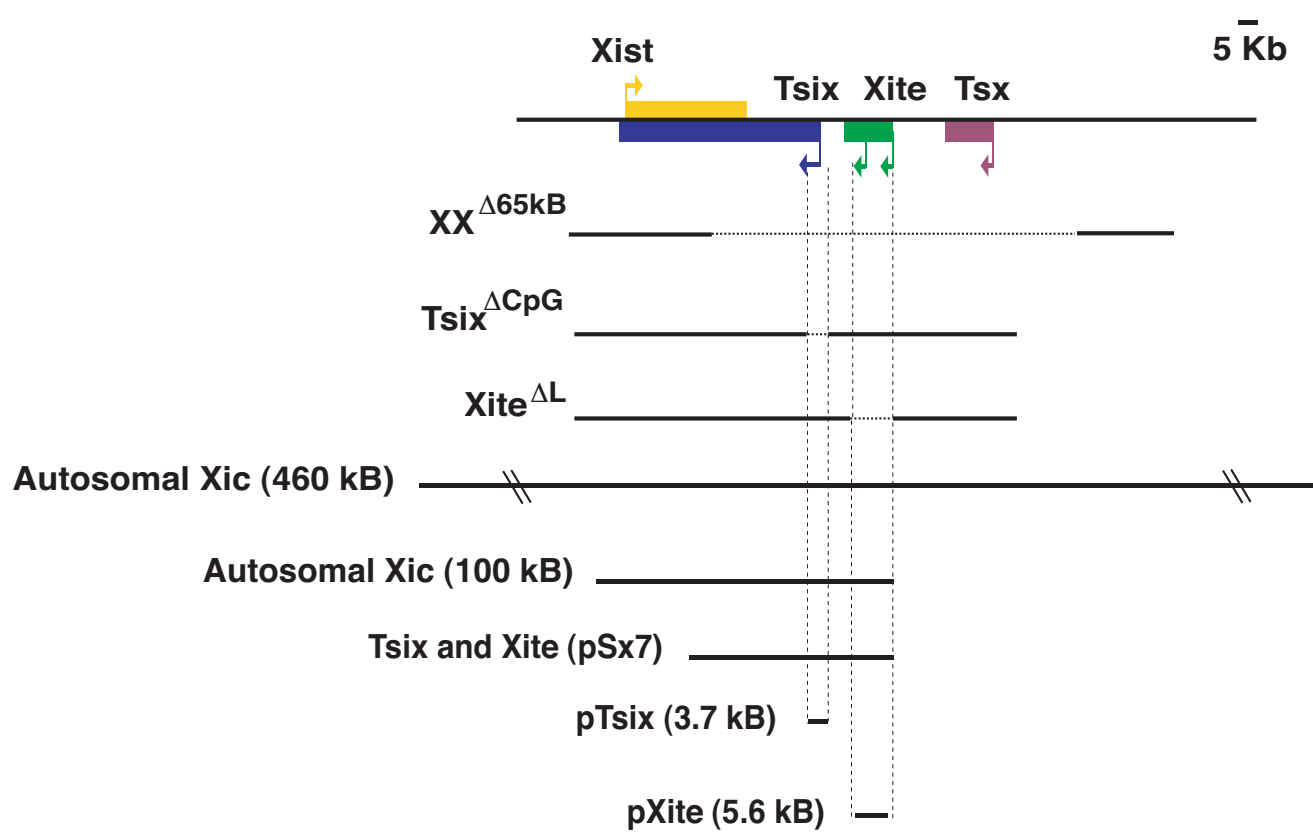

Figure 1. Map of the X-inactivation center (Xic) and locations of existing genetic deletions and transgene insertions. (Dashed lines) Genetic deletions (designated by $\Delta$ ); (solid lines) autosomal insertions of various regions of the Xic. The 460-kb Xic autosomal transgene, encompassing $130 \mathrm{~kb} \mathrm{5}$ and $310 \mathrm{~kb} \mathrm{3}^{\prime}$ of Xist, is not drawn to scale (indicated by the diagonal cross bars).

$\mathrm{X}$ silencing is the rule. Although the field has yet to reach a consensus on the nature of the "imprint," differential CpG methylation within the Xist-Tsix-Xite regions has been implicated (Norris et al. 1994; Ariel et al. 1995; Courtier et al. 1995; Zuccotti and Monk 1995; McDonald et al. 1998; Prissette et al. 2001; Boumil et al. 2006). We note that slight differences in the methylation pattern and the lack of functional evidence thus far leave open the question of which, if any, of these marks constitute the primary imprint. Because the Tsix domains of differential methylation coincide with binding sites for the chromatin insulator and transcription factor, CTCF (Chao et al. 2002; Boumil et al. 2006), parallels to genomic imprinting at the H19/Igf2 locus and Rasgrf1 locus have frequently been drawn (Bell and Felsenfeld 2000; Hark et al. 2000; Holmgren et al. 2001; Yoon et al. 2002, 2005). At these autosomal imprinted loci, the differential binding of CTCF to differentially methylated imprinting centers appears to be of primary importance in setting up the mutually exclusive fates of the maternal and paternal chromosomes.

In a similar vein, what has been considered "random" $\mathrm{X}$-inactivation could employ such a chromosome-specific mark, but that mark would be imposed zygotically rather than gametically. In a departure from conventional thought, two recent models suggest that "differential states" are already present prior to the onset of XCI (Williams and Wu 2004; Mlynarczyk-Evans et al. 2006). Although the nature of the "states" is unclear, the states are proposed to result in a situation in which both $\mathrm{X}$ chromosomes are not inactivated in a completely stochastic sense, but exist in predeterministic states that can alternate between the two Xs before XCI that predisposes one $\mathrm{X}$ to be silent at the onset of XCI. In one case, it is argued that the two active Xs of female embryonic stem (ES) cells switch between states in which the sister chromatids are in close apposition and another in which they are farther apart (Mlynarczyk-Evans et al. 2006). The model further proposes that the configuration in which the Xics are farther apart "predetermines" the future Xa. Additional characterization will be required to demonstrate if and how they are involved in X-inactivation choice.

A second possibility - one generally preferred by the field - is the concept of a limiting factor that is present in quantities sufficient for only one $\mathrm{X}$ chromosome (Fig. 2B) (Lyon 1972; Rastan 1983), and it is the stochastic binding of this factor, or factors to the Xs, that determines the random pattern of silencing. This putative factor could be a "negative" factor (acting to repress the Xic) or a "positive" factor (acting to induce it), depending on its mechanism of action. For instance, in the classic one-factor hypothesis, the $\mathrm{X}$ chromosomes are predisposed to inactivate by default, and the binding of the so-called "blocking factor" (BF) to one $\mathrm{X}$ is specifically required to block its $X i c$ from initiating silencing. Conversely, if $\mathrm{X}$-inactivation is actively triggered and does not occur by default, the interaction of the single positive factor-so-called competence factor $(\mathrm{CF})$ - would be required to initiate inactivation. An alternative to the one-factor hypothesis proposes that two factors (one $\mathrm{BF}$ and one $\mathrm{CF}$ ) are required for XCI (Lee and Lu 1999; Lee 2005). The nature of the negative/positive factor could be a unique factor, a complex of factors, or a unique privileged site within the nucleus. In any case, the limited quantity of the factors and their sole action on one or the other X are directly responsible for the "asymmetric" action on two otherwise epigenetically equivalent Xs.

A third possibility invokes direct contact between the $\mathrm{Xs}$ as the basis of communication and determination of 
A
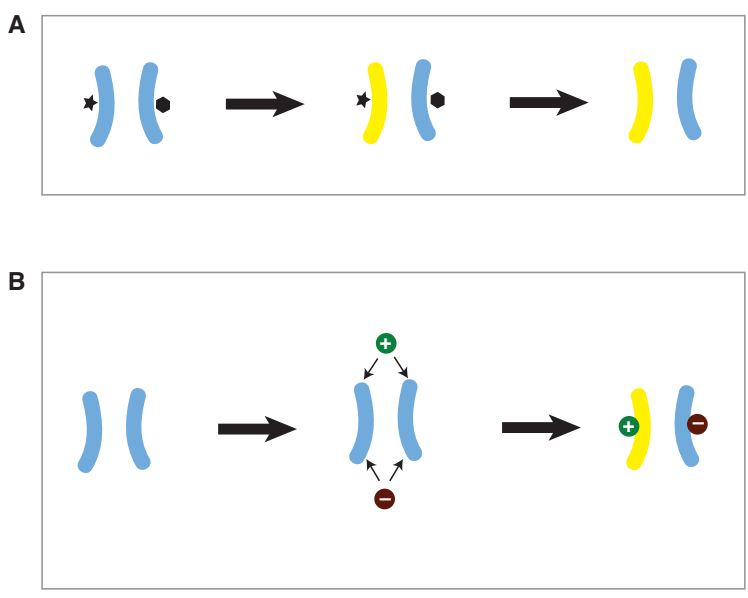

C

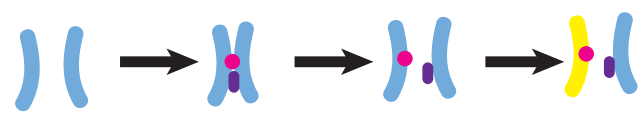

Figure 2. Conceptual models of mutually exclusive X-chromosome inactivation. (Light blue chromosomes) Active Xs; (yellow chromosomes) $\mathrm{X}$ chromosomes that are inactivated. $\mathrm{X}$-inactivation proceeds from left to right. (Panel A) X chromosomes are not equivalent before the onset of XCI. Even before X-inactivation is initiated, the presence of marks or different "states" (represented by the star and the hexagon) distinguishes the two Xs. At the onset of X-inactivation, the $\mathrm{X}$ chromosome containing the mutually exclusive mark is silenced. This mark may or may not persist into the differentiated state. (Panel B) Limited positive and negative factors interact with one of the two X chromosomes. Before XCI begins, both $\mathrm{X}$ chromosomes are competent to become inactivated. The presence of a single positive/competence factor (green) or negative/blocking factor (red) can associate stochastically with either X. Binding of the positive factor triggers inactivation, whereas the negative factor protects the $\mathrm{X}$ from inactivation. (Panel C) $\mathrm{X}$ chromosomes interact with one another to coordinate mutually exclusive choice. Before XCI initiation, both $\mathrm{X}$ chromosomes are epigenetically equivalent. Pairing of the two Xs facilitates cross-talk for the formation of asymmetrical chromosomes, with the association of two factors (represented by a pink circle and purple oval). The asymmetry allows the cell to act uniquely upon one $\mathrm{X}$, but not the other. Although schematized here as soluble factors, this asymmetry may also be chromosomally based (e.g., a different chromatin state, histone, and/or DNA modifications).

their distinct fates (Fig. 2C). Trans-chromosomal interaction occurs in phenomena such as transvection in Drosophila and Neurospora (Aramayo and Metzenberg 1996; Wu and Morris 1999; Chen et al. 2002; Duncan 2002; Coulthard et al. 2005; Vazquez et al. 2006) and in mammalian autosomal imprinting (LaSalle and Lalande 1995, 1996). Such trans-sensing mechanisms have also been proposed for X-inactivation (Marahrens 1999; Lee 2002b). In principle, physical contact between the two Xs could coordinate the silencing process and ensure that one and only one $\mathrm{X}$ becomes the future $\mathrm{Xi}$, thereby providing a mechanism for establishing distinct fates for the two Xs.
We now highlight advances within the past year that shed light on the nature of mutually exclusive choice and the mechanism by which asymmetric marks are placed on the Xs. Intriguingly, homologous Xs do appear to come in physical contact just prior to the onset of XCI. Furthermore, the initiation of XCI is preceded by chromatin modifications unique to the Xic on the future Xi. Here, we propose a speculative model of early events in $\mathrm{X}$-inactivation linking the physical pairing between the two $\mathrm{X}$ chromosomes to the establishment of Xic asymmetry.

\section{THE EPHEMERAL ACT OF PAIRING}

Although trans-sensing has long been suspected to occur at the Xic, experimental evidence for such interactions has, until recently, been completely lacking. The "chaotic choice" phenotype in female cells lacking Tsix provided the first experimental evidence for the idea of necessary cross-talk (Lee 2005). In homozygous $\mathrm{Tsix}^{-/}$ ES cells, cell differentiation results in aberrant XCI patterns in which female nuclei exhibit two $\mathrm{Xi}$, one $\mathrm{Xi}$, or no Xi. In recent papers, two groups independently examined whether homologous pairing of the $\mathrm{X}$ chromosomes might mediate trans-sensing. They used fluorescence in situ hybridization (FISH) to monitor the $\mathrm{X}-\mathrm{X}$ distances during the various phases of XCI in female mouse ES cells, a model system that faithfully recapitulates the steps of XCI upon cell differentiation in culture (Lee et al. 1996; Panning et al. 1997; Clerc and Avner 1998; Marahrens et al. 1998). They found that the two X chromosomes transiently pair with each other during the onset of XCI, most likely just prior to Xist up-regulation (Bacher et al. 2006; Xu et al. 2006). Curiously, it appears that the majority of $\mathrm{X}-\mathrm{X}$ pairs occur very close to the periphery of the nuclear envelope (Bacher et al. 2006), although the significance of this is presently not known, as no specific nuclear compartment has been identified.

Both groups found that the $\mathrm{X}-\mathrm{X}$ associations are transient, as $\mathrm{X}-\mathrm{X}$ pairing disappears during later stages of cellular differentiation and in fully differentiated somatic cells (Bacher et al. 2006; Xu et al. 2006). By asking whether pairing coincides with several chromatin changes that occur in sequence during XCI, Xu et al. (2006) observed that the association takes place in the Xist+ fraction but not in the Ezh2+ or the H3-3meK27+ subpopulation, suggesting that pairing occurs specifically in the fraction of cells that has entered the XCI pathway, but has not yet recruited the full silencing machinery. The brevity and timing of the $\mathrm{X}-\mathrm{X}$ association are intriguing, as indeed the time window coincides with $\mathrm{X}$ chromosome counting and choice - the point at which the future $\mathrm{Xi}$ and $\mathrm{Xa}$ are designated.

How much of the $\mathrm{X}$ chromosome is engaged in pairing interactions and how close do the Xs actually get? By testing probes along the length of the $\mathrm{X}$, from centromere to telomere, $\mathrm{Xu}$ et al. (2006) found that $\mathrm{X}-\mathrm{X}$ pairing occurs specifically between the Xic regulatory regions and not between any other regions of the $\mathrm{X}$ chromosome. Then, biochemical analysis using the "chromosome conformation capture" (3C) technique (Dekker et al. 2002) determined with greater precision that the two Xic regions are in 
direct physical contact with each other and that this contact takes place when pairing is seen to occur by FISH analysis.

\section{WHY DO X-CHROMOSOMES PAIR?}

The Xic region contains genes for the noncoding Xite, Tsix, and Xist RNAs, the major players involved in regulating counting, choice, and silencing during XCI. Could these regulatory sequences facilitate the transient $\mathrm{X}-\mathrm{X}$ interactions necessary for mutually exclusive choice? Genetic analysis shows that, interestingly, the Xic domains required for pairing map precisely to genes that regulate counting and choice-Tsix and Xite. An X chromosome carrying a $65-\mathrm{kb}$ deletion downstream from Xist loses the ability to pair with its wild-type homolog (Fig. 1) (Clerc and Avner 1998; Bacher et al. 2006). Within this $65-\mathrm{kb}$ region, subdeletions involving either $12.5 \mathrm{~kb}$ of Xite (Ogawa and Lee 2003) or $3.7 \mathrm{~kb}$ of Tsix (Lee and Lu $1999)$ are sufficient to perturb the pairing process (Xu et al. 2006). Notably, the loss of pairing in the homozygous deletion of Tsix specifically correlates with aberrant XCI patterns in the differentiating female ES cells: The occurrence of cells with two $\mathrm{Xi}$, one $\mathrm{Xi}$, and no $\mathrm{Xi}$ in any differentiating population implies a disruption in both counting (i.e., aberrant numbers of Xis) and mutually exclusive choice (i.e., the two- and no-Xi phenotype) (Lee 2002a, 2005; Ogawa and Lee 2003). Thus, deletions of elements necessary for $\mathrm{X}-\mathrm{X}$ pairing compromise the regulation of counting and choice.

The connection between counting/choice and $\mathrm{X}-\mathrm{X}$ pairing is further supported by analysis of transgenic cell lines containing multiple copies of Tsix or Xite transgenes inserted into autosomes (summarized in Fig. 3). Male ES cells carrying full-length Xic transgenes (100-460 kb) display novel interchromosomal association between the $\mathrm{X}$ and the transgene-bearing autosome (Bacher et al. 2006; $\mathrm{Xu}$ et al. 2006). Significantly, these male cells also display ectopic XCI (Lee et al. 1996, 1999b; Heard et al. 1999), further correlating pairing with the ability to undergo XCI. In female ES cells, the same transgenes also induce de novo $\mathrm{X}$-autosome $(\mathrm{X}-\mathrm{A})$ pairing, and regions as small as $3.7 \mathrm{~kb}$ of $T$ six and $5.6 \mathrm{~kb}$ of Xite-at least when multimerized - are sufficient to create new X-A pairs $(\mathrm{Xu}$ et al. 2006). A direct physical interaction between the $X$ and the autosome can also be visualized by $3 \mathrm{C}$ analysis ( $\mathrm{Xu}$ et al. 2006). Thus, sequences within Tsix and Xite not only are necessary, but are also sufficient to form new pairs.

The analysis of Tsix/Xite transgenes in a female context revealed an intriguing difference from that in a male. The presence of extra copies of Tsix and Xite in an XX context disrupts cell differentiation, whereas it has no measurable effect in XY cells (Lee 2005). The aberrant cell differentiation apparently results from the absence of Xist upregulation and XCI in the transgenic female cells. It was then observed that the occurrence of ectopic $\mathrm{X}-\mathrm{A}$ pairs competitively inhibits the formation of endogenous $\mathrm{X}-\mathrm{X}$ pairs (Xu et al. 2006). Taken together, these results suggest that $\mathrm{X}-\mathrm{X}$ pairing is a prerequisite for the initiation of XCI, which in turn is required for proper cell differentiation. It is therefore hypothesized that homologous chromosome pairing is one of the earliest events of XCI and is specifically required for counting and choice,

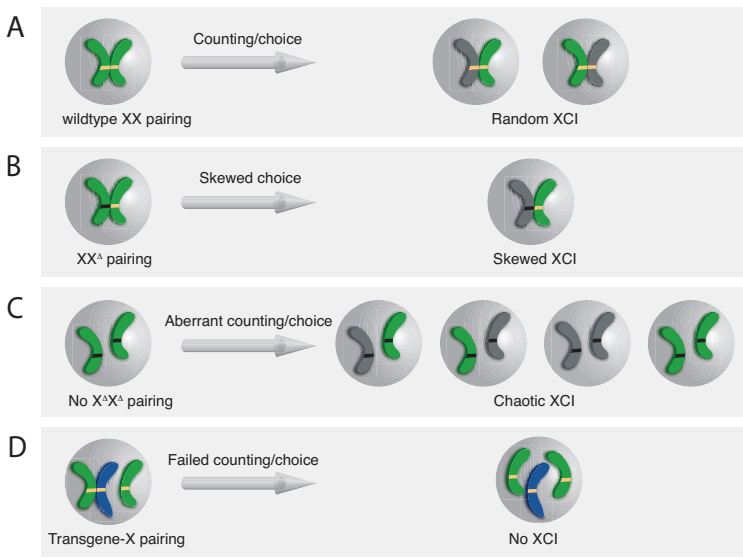

Figure 3. Summary of the effects of Xic, Tsix, and Xite genetic deletions and autosomal transgenes on the $\mathrm{X}-\mathrm{X}$ pairing event and XCI. (Panel $A$ ) In wild-type XX ES cells, the homologous pairing between two Xic regions (designated by the yellow regions) on two active $\mathrm{X}$ chromosomes (green chromosomes) generates cross-talk resulting in asymmetrically "marked" chromosomes (future $\mathrm{Xi}$ shown in gray) for mutually exclusive choice. (Panel B) Cell lines containing either a single-copy deletion of Xic or Tsix (designated as XX $X^{\Lambda}$ cells, with the deletion in black) exhibit normal X-X pairing with skewed choice and inactivation on the mutated $\mathrm{X}$. The single-copy deletion of Xite disrupts the dynamics of the $\mathrm{X}-\mathrm{X}$ pairing event, also resulting in skewed inactivation of the mutated X. (Panel $C$ ) Homozygous deletion of Tsix (designated as $\mathrm{X}^{\Delta} \mathrm{X}^{\Delta}$ cells) disrupts $\mathrm{X}-\mathrm{X}$ pairing and results in chaotic choice, with cells containing either $0,1 \mathrm{Xi}$, or $2 \mathrm{Xi}$, and abnormal XCI. (Panel D) Cell lines containing multiple copies of either the Xic, Tsix, or Xite transgenes (yellow regions) on autosomes (blue) exhibit de novo $\mathrm{X}$-autosome pairing and disruptions in $\mathrm{X}-\mathrm{X}$ pairing. These abnormal transinteractions may out-compete the normal $\mathrm{X}-\mathrm{X}$ association, resulting in the presence of two Xa per cell and the failure of counting/choice and XCI.

without which the silencing mechanism of XCI cannot be called upon in female cells undergoing differentiation.

The discovery of pairing provokes many new questions regarding the mechanism of XCI. Does the pairing process involve specific DNA domains within Tsix and Xite? Does it require transcription, the ncRNA outputs of Tsix and Xite, or particular chromatin modifications to the genetic locus? Interestingly, transgenic subfragments of Tsix and Xite that are most effective at nucleating pairing carry promoter elements (Xu et al. 2006). If transcription of these ncRNAs is indeed required, then pairing, counting, and choice must be added to the list of the already diverse functions of ncRNA elements in gene regulation. Finally, what do the Xs communicate to each other while paired, and how are the distinct fates of each $\mathrm{X}$ decided by this mysterious act of cross-talking?

\section{FROM THERE TO HERE: PAIRING AND ASYMMETRIC XIC FATES}

Prior to pairing, the two $\mathrm{X}$ chromosomes appear to be epigenetically equivalent. When they pair and come apart again, the Xs appear to be marked for different transcriptional fates. If mutually exclusive choice arises from these trans-allelic interactions, the interactions must create physical differences between the two chromosomes 
that signal for one $\mathrm{X}$ to remain active and the other $\mathrm{X}$ to become repressed. In theory, the asymmetry could be created by many possibilities, including differential binding of a protein factor, transient localization of the Xs to a certain nuclear region, or specific "marks" and epigenetic modifications.

Recent evidence supports the idea of allele-specific differences in chromatin states. It was shown previously that the Xist loci exist in different chromatin environments consistent with the expression status of Xist: The active Xist gene is associated with an "open" chromatin state with increased levels of H3-K4 dimethylation. In contrast, the silent Xist allele exists in a "closed" chromatin state characterized by $\mathrm{H} 3-\mathrm{K} 9$ dimethylation and H3-K27 trimethylation (Goto and Monk 1998; Navarro et al. 2005; Sado et al. 2005). These observations - made using cells that have already undergone XCI-do not indicate whether the chromatin modifications are a cause or consequence of the asymmetrical expression of Xist. Additionally, Tsix has been recently shown to influence the local chromatin structure of the Xist promoter region in post-XCI cells and embryos (Navarro et al. 2005; Sado et al. 2005). These studies suggest an interplay between Tsix and the local chromatin environment of Xist that would support transcription of the locus, where Tsix may function to maintain an open chromatin state at Xist. However, because these experiments were also carried out using cells that had already undergone XCI, they contribute to the uncertainty of whether the chromatin modifications actually correlate with the monoallelic expression of Xist and the role of Tsix in this process (Sado et al. 2005). That is, could these chromatin marks be the causal asymmetry for mutually exclusive choice and therefore predict the monoallelic expression pattern of Xist?

To address this question, a recent study examined the chromatin environment at Xist at time points before, during, and after the onset of XCI using female ES cells (Sun et al. 2006). The study used an allele-specific chromatin immunoprecipitation (ChIP) to assay the relative levels of histone modifications on the two X chromosomes of hybrid female ES cells (one X of Mus castaneus origin and the other of 129 origin). Three of the most studied histone modifications were examined: histone H3-K4 dimethylation, $\mathrm{H} 3-\mathrm{K} 27$ trimethylation, and $\mathrm{H} 4$ acetylation. The results are consistent with the idea that, before XCI, the two Xs are epigenetically identical because each modification was detected at relatively equal levels on both X chromosomes in wild-type female ES cells. In fibroblasts, which have already undergone XCI, the expressed Xist allele is enriched with $\mathrm{H} 3-\mathrm{K} 4$ dimethylation and $\mathrm{H} 4$ acetylation and reduced in $\mathrm{H} 3-\mathrm{K} 27$ trimethylation, consistent with the previous reports showing that the expressed Xist allele is in an open chromatin state (Navarro et al. 2005; Sado et al. 2005).

The situation during the onset of XCI, however, revealed an unexpected result - the presence of a transient heterochromatic environment at the Xist loci (Sun et al. 2006). During this phase of XCI, the authors note that Xist expression is up-regulated about 30 -fold and that, oddly, this transcription occurs from the locus buried in "heterochromatin." This Xist locus contains increased H3-K27 trimethylation and a modest decrease in H4 acetylation levels at this stage of XCI, marks normally characteristic of silenced genes. The chromatin environments, summarized in Figure 4, are completely opposite
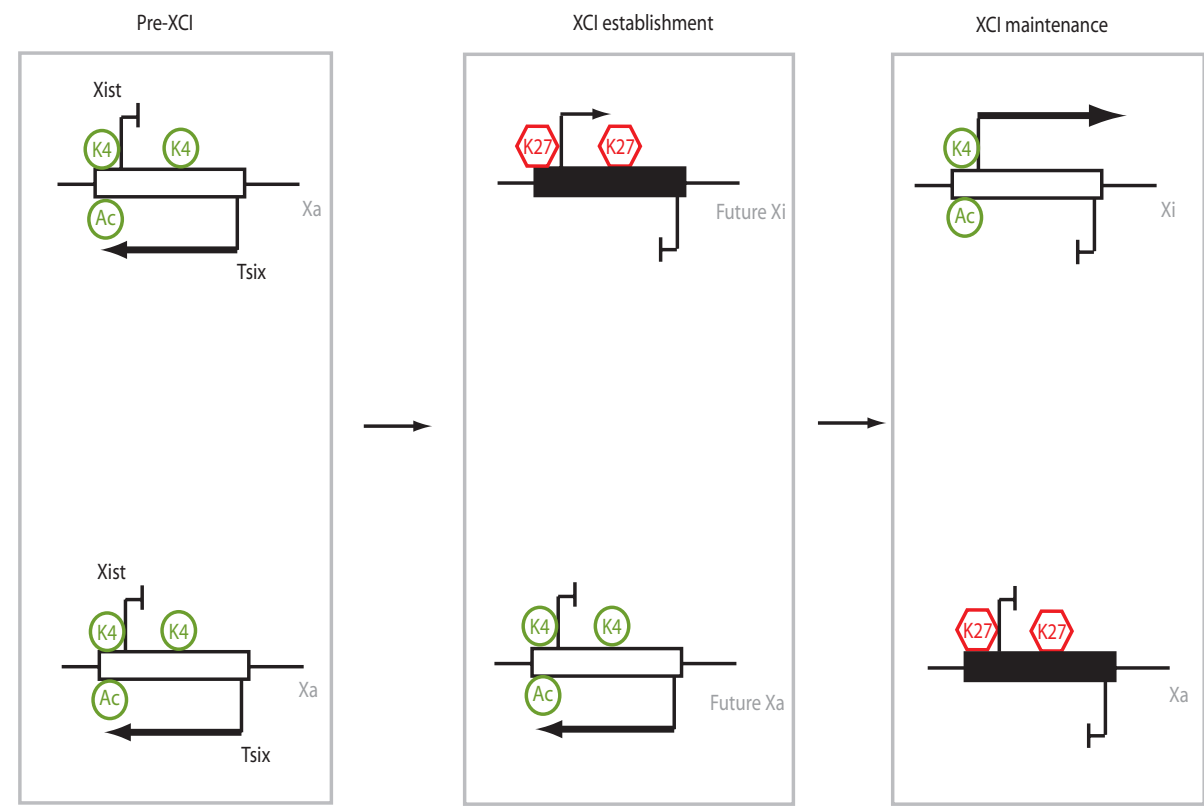

Figure 4. Different chromatin modifications within the Xist region (represented as a rectangle) distinguish and predict the future Xi and Xa. The Xist region, with modifications shown occurring at the promoter region (upstream of the start site) or within the Xist gene body (downstream from the start site). Before XCI, the two X chromosomes are epigenetically identical and the Xist region is euchromatic (open rectangle), with robust Tsix expression. (Green) Euchromatic modifications, with histone H3-K4 dimethylation denoted as $\mathrm{K} 4$ and histone $\mathrm{H} 4$ acetylation as Ac. The Xist region becomes heterochromatic (filled rectangle), and histone H3-K27 trimethylation is represented in red as K27. During the establishment of XCI, the two X chromosomes exhibit different chromatin modifications, with the future Xi being heterochromatic (with paradoxical Xist expression) and the future Xa being euchromatic. These modifications reverse during the final maintenance phase of XCI. 
for the future $\mathrm{Xa}$ and $\mathrm{Xi}$, and the marks change as $\mathrm{XCI}$ progresses. The Xist region is euchromatic on both alleles before XCI, supporting the hypothesis that the two Xs are epigenetically equivalent at the pre-XCI stage. Following counting/choice, the future $\mathrm{Xi}$ acquires heterochromatic features at the Xist region along with the onset of Xist expression. The future Xa allele continues to be euchromatic within the Xist region after the pairing and counting/choice events. During the final maintenance phase of $\mathrm{XCI}$, the chromatin patterns invert, with the Xi allele exhibiting euchromatic features and increased expression of Xist, and the Xa allele being heterochromatic and therefore transcriptionally silent.

What is the function of Tsix in influencing the local chromatin environment and regulating the monoallelic expression patterns of Xist? The authors repeated the same allele-specific ChIP experiments using a heterozygous female mutant of Tsix, and found that each Xist allele contains different chromatin modifications corresponding to the absence of Tsix (Sun et al. 2006). On the Tsix ${ }^{-}$allele, the Xist locus is heterochromatic with decreased H3-K4 dimethylation, H4 hypoacetylation, and increased H3-K27 trimethylation. Indeed, it is this mutated X that is invariably silenced during XCI: During the onset of XCI, Xist becomes expressed exclusively from the $T$ six ${ }^{-}$chromosome. Intriguingly, these asymmetric chromatin marks occur in the $T$ six ${ }^{+-}$ES cells even before induction of XCI by cell differentiation. These observations demonstrate that the chromatin marks preempt asymmetric Xist expression and thereby argue that the $T$ six-driven chromatin changes are causally linked to the establishment of unequal and mutually exclusive $\mathrm{X}$-chromosome fates.

Taken together, these experiments delineate a series of preemptive asymmetrical chromatin changes at Xist that differentiate the two $\mathrm{X}$ chromosomes and predict the monoallelic expression pattern of Xist (summarized in Fig. 4). Before the onset of XCI, the biallelic expression of Tsix on both X chromosomes keeps each Xist locus in an open, euchromatic state. During the onset of XCI, Tsix is silenced on one of the two X chromosomes. The loss of Tsix expression from that Xic allele influences the formation of the heterochromatic state in Xist, which leads paradoxically, in turn, to the transcriptional activation of that Xist allele. The euchromatic status of the second allele prevents the up-regulation of Xist on the future Xa. For reasons entirely unknown at the present time, the chromatin environment at Xist inverts to more conventional patterns after the establishment of XCI, in agreement with observations made by other studies in late-stage embryos and in differentiated cells (Navarro et al. 2005; Sado et al. 2005).

A number of interesting problems remain to be resolved. First, does Xist truly favor a repressive chromatin environment for transcription and is heterochromatin sufficient to induce Xist expression? If so, Xist may be classified as a heterochromatin-preferring gene, much like the Light gene of Drosophila melanogaster, which appears to require heterochromatin for transcriptional activation (Wakimoto and Hearn 1990; Yasuhara and Wakimoto 2006). Second, why do the chromatin states invert after the establishment of XCI patterns, especially when Xist expression continues into the maintenance phase of XCI, and become constitutive in all somatic female cells? If heterochromatin is required to initiate Xist expression, one might expect it to be required for maintenance of expression in somatic cells. Finally, when in the XCI pathway does the heterochromatic state arise-during the pairing process or after the pairs come apart?

\section{MODEL: CROSS-TALKING GENERATES X-ASYMMETRY FOR MUTUALLY EXCLUSIVE CHOICE}

In this review, we have presented evidence supporting a model of XCI where X-X communication results in mutually exclusive choice. Our model incorporates facets of the one-factor model for X-chromosome counting/choice, which is currently widely accepted by the field (Lyon 1972; Rastan 1983). It posits the generation of protein factors, produced primarily from autosomes (but does not rule out X-linked factors) in amounts proportional to the actual number of chromosomes present. These proteins form the complex dubbed the blocking factor (BF), which binds one Xic and represses the initiation of silencing on that X (Lyon 1972; Rastan 1983). All remaining Xics, lacking the association with the limiting BF, are induced by default to initiate silencing on the linked chromosome.

Although the single-factor (BF) model is simple and elegant, recent observations from Tsix and Xite genetic analyses have not been easy to reconcile. The alternative "two-factor" model has been proposed based on the principal observation that Xic mutations behave differently in the XX and XY contexts (Lee and Lu 1999; Lee 2005). First, given that Tsix-1+ and Tsix-/- mutations in female cells lead to loss of Xist repression, one would expect male cells lacking Tsix to inappropriately up-regulate Xist and silence its sole X. However, Tsix-/Y ES cells do not undergo XCI to any significant degree (Lee and Lu 1999; Sado et al. 2001), and Tsix-/Y mice are perfectly normal. (Note: This applies when the Tsix mutation is paternally inherited to avoid imprinting effects at Tsix [Lee 2000; Sado et al. 2001].) Along similar lines, female ES cells carrying multicopy Xite and Tsix transgenes form no Xi at all. Thus, although one could argue that one $\mathrm{X}$ is protected by BF, the second $\mathrm{X}$ is clearly not silenced "by default." Finally, in reporter assays where the Xist promoter drives expression of luciferase, differentiation of female cells results in increased luciferase expression only in XX and not XY cells (Sun et al. 2006).

Clearly then, XY cells lack a factor that would ordinarily be present in XX cells. The two-factor model thus incorporates the need for BF binding on the future $\mathrm{Xa}$ and introduces the need for a second factor - dubbed the competence factor (CF). CF is believed to play a part in inducing the inactivation of the future $\mathrm{Xi}$ and would be produced only in the context of supernumerary Xs. Indeed, CF is thought to consist of X-linked factors not titrated away by the fixed quantity of autosomal factors produced during the counting process. Naturally, every $\mathrm{X}$ in excess of one would produce one $\mathrm{X}$-linked $\mathrm{CF}$, enabling the silencing of all but one $\mathrm{X}$ (one that binds $\mathrm{BF}$ ) in the genome. 


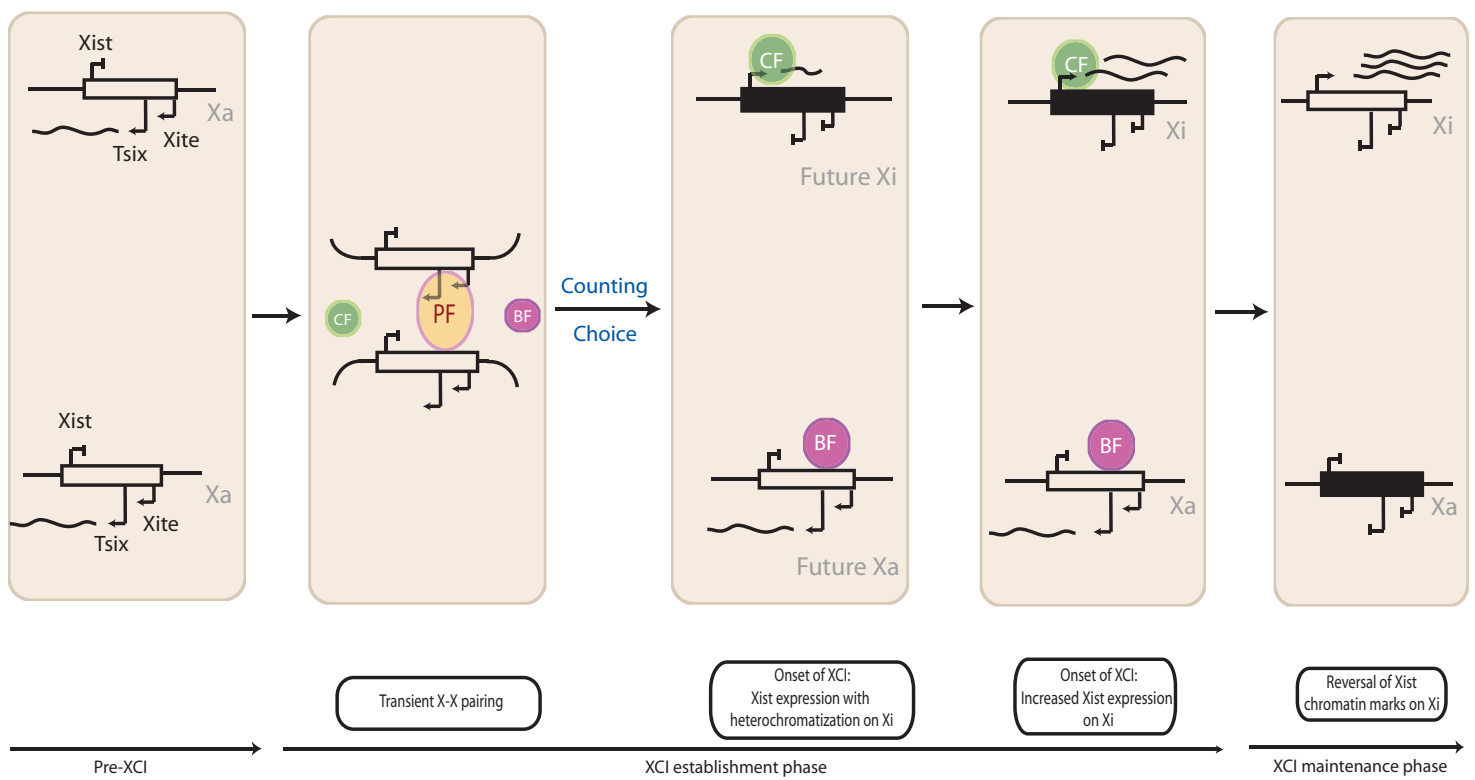

Figure 5. A model for mutually exclusive choice arising from cross-talk between paired $X$ chromosomes, resulting in asymmetrical Xs. The two X chromosomes are both euchromatic and epigenetically identical at the pre-XCI stage. The two chromosomes are then paired together, perhaps with the help of a pairing factor $(\mathrm{PF})$, to facilitate the cross-talk needed to distinguish between the chromosomes. Following the transient $\mathrm{X}-\mathrm{X}$ pairing event, the future $\mathrm{Xi}$ and future $\mathrm{Xa}$ are distinguished by different chromatin modifications within the Xist region. Binding of a competence factor $(\mathrm{CF})$ to an unknown site in this region of the future Xi assists with the transcriptional up-regulation of Xist despite the heterochromatic environment. The binding of a blocking factor (BF), again to an unknown site, may function to help Tsix keep Xist repressed on the euchromatic future Xa. The chromatin modifications switch for the Xi and Xa alleles during the final maintenance phase of XCI.

We hypothesize that this counting process is intimately linked to pairing, perhaps occurring simultaneously in time and space (Fig. 5). BF and CF must bind mutually exclusively. The proposed cross-talk during the paired state may provide a platform on which the asymmetric distribution of BF and CF takes place. During the pre$\mathrm{XCI}$ stage, the $\mathrm{X}$ chromosomes are epigenetically identical and exist in random positions relative to each other in the nucleus. As XCI begins, the two Xs transiently pair via putative pairing factor(s) (PF) and they do so perhaps within a particular region in the nucleus, with closest contact points occurring at Tsix and Xite. It is envisioned that $\mathrm{BF}$ and $\mathrm{CF}$ compete to bind. Where the hypothetical BF and $\mathrm{CF}$ would bind is a subject of debate. Previously, it has been speculated that BF may bind Tsix or Xite of the future $\mathrm{Xa}$ and ensure the persistent expression of Tsix (Lee and Lu 1999; Lee 2005). On the other hand, CF may bind either to Tsix/Xite to down-regulate their Xapromoting activities or it may bind Xist directly, perhaps recruited there by the newly created transient heterochromatic status of the Tsix/Xist domain.

By this model, cross-talking via $\mathrm{X}-\mathrm{X}$ pairing eventually leads to the mutually exclusive binding of $\mathrm{BF}$ and $\mathrm{CF}$ and divergent X-fates. BF's unique binding to one Xic enables the monoallelic persistence of Tsix expression on the future $\mathrm{Xa}$. The absence of BF binding and the unique binding of CF to the remaining Xic would then silence Tsix and enable the induction of Xist. Therefore, pairing generates the asymmetry in Tsix expression, which in turn dictates the asymmetric chromatin modifications and expression patterns of Xist.
The future promises to bring exciting new revelations pertaining to the mechanisms of counting, choice, and XCI. With no shortage of models, it seems, however, that $\mathrm{XCI}$ is likely to become even more complicated before the mechanisms are clarified. What we have discussed herein applies primarily to the random form of XCI. It is possible that imprinted XCI employs a significantly different mechanism of silencing, as indeed the marsupial genome appears to lack Xist (Duret et al. 2006; Hore et al., in prep.; L.S. Davidow et al., in prep.) . In this case, one wonders whether pairing and differential chromatin marks also direct the initiation of XCI in the marsupial. Recent studies have also introduced the contrasting viewpoint that an XX-specific CF may not be required for XCI (Morey et al. 2004; Vigneau et al. 2006). On the basis of results from a deletion of the DXPas 34 repeat in Tsix, the work suggests that inhibition of Tsix transcription (at least in the context of this deletion) has similar effects in cis in male and female cells, thus questioning whether $\mathrm{XX}-\mathrm{XY}$ differences exist and whether they could be used as a basis for postulating a need for a CF. Yet, as discussed above, $\mathrm{XX}-\mathrm{XY}$ differences do actually exist. Clearly, many unanswered questions regarding mechanisms remain and will continue to challenge the field for years to come.

\section{ACKNOWLEDGMENTS}

We thank Jennifer Erwin and Janice Yoo-Jin Ahn for critical reading of this manuscript, and all members of the Lee Laboratory for helpful discussions. M.C.A. is funded 
by the National Institutes of Health (GM076955-01), B.K.S. is funded by the Medical Scientist Training Program, and J.T.L. is funded by the National Institutes of Health and Howard Hughes Medical Institute.

\section{REFERENCES}

Aramayo R. and Metzenberg R.L. 1996. Meiotic transvection in fungi. Cell 86: 103.

Ariel M., Robinson E., McCarrey J.R., and Cedar H. 1995. Gamete-specific methylation correlates with imprinting of the murine Xist gene. Nat. Genet. 9: 312.

Avner P. and Heard E. 2001. X-chromosome inactivation: Counting, choice and initiation. Nat. Rev. Genet. 2: 59.

Bacher C.P., Guggiari M., Brors B., Augui S., Clerc P., Avner P., Eils R., and Heard E. 2006. Transient colocalization of $\mathrm{X}$-inactivation centers accompanies the initiation of $\mathrm{X}$ inactivation. Nat. Cell Biol. 8: 293.

Bell A.C. and Felsenfeld G. 2000. Methylation of a CTCFdependent boundary controls imprinted expression of the Igf2 gene. Nature 405: 482.

Borsani G., Tonlorenzi R., Simmler M.C., Dandolo L., Arnaud D., Capra V., Grompe M., Pizzuti A., Muzny D., and Lawrence C., et al. 1991. Characterization of a murine gene expressed from the inactive X chromosome. Nature 351: 325 .

Boumil R.M. and Lee J.T. 2001. Forty years of decoding the silence in X-chromosome inactivation. Hum. Mol. Genet. 10: 2225.

Boumil R.M., Ogawa Y., Sun B.K., Huynh K.D., and Lee J.T. 2006. Differential methylation of Xite and CTCF sites in Tsix mirrors the pattern of X-inactivation choice in mice. Mol. Cell. Biol. 26: 2109

Brockdorff N., Ashworth A., Kay G.F., McCabe V.M., Norris D.P., Cooper P.J., Swift S., and Rastan S. 1992. The product of the mouse Xist gene is a $15 \mathrm{~kb}$ inactive X-specific transcript containing no conserved ORF and located in the nucleus. Cell 71: 515 .

Brockdorff N., Ashworth A., Kay G.F., Cooper P., Smith S., McCabe V.M., Norris D.P., Penny G.D., Patel D., and Rastan S. 1991. Conservation of position and exclusive expression of mouse Xist from the inactive X chromosome. Nature 351: 329.

Brown C.J., Ballabio A., Rupert J.L., Lafreniere R.G., Grompe M., Tonlorenzi R., and Willard H. 1991. A gene from the region of the human $\mathrm{X}$ inactivation center is expressed exclusively from the inactive X chromosome. Nature 349: 38.

Brown C.J., Hendrich B.D., Rupert J.L., Lafreniere R.G., Xing Y., Lawrence J., and Willard H.F. 1992. The human XIST gene: Analysis of a $17 \mathrm{~kb}$ inactive X-specific RNA that contains conserved repeats and is highly localized within the nucleus. Cell 71: 527 .

Chao W., Huynh K.D., Spencer R.J., Davidow L.S., and Lee J.T. 2002. CTCF, a candidate trans-acting factor for X-inactivation choice. Science 295: 345.

Chen J.L., Huisinga K.L., Viering M.M., Ou S.A., Wu C.T., and Geyer P.K. 2002. Enhancer action in trans is permitted throughout the Drosophila genome. Proc. Natl. Acad. Sci. 99: 3723 .

Clemson C.M., McNeil J.A., Willard H., and Lawrence J.B. 1996. XIST RNA paints the inactive $\mathrm{X}$ chromosome at interphase: Evidence for a novel RNA involved in nuclear/chromosome structure. J. Cell Biol. 132: 259.

Clerc P. and Avner P. 1998. Role of the region 3' to Xist exon 6 in the counting process of X-chromosome inactivation. Nat. Genet. 19: 249.

2003. Multiple elements within the Xic regulate random X inactivation in mice. Semin. Cell Dev. Biol. 14: 85.

Cohen D.E. and Lee J.T. 2002. X-chromosome inactivation and the search for chromosome-wide silencers. Curr. Opin. Genet. Dev. 12: 219.

Coulthard A.B., Nolan N., Bell J.B., and Hilliker A.J. 2005. Transvection at the vestigial locus of Drosophila melanogaster. Genetics 170: 1711.
Courtier B., Heard E., and Avner P. 1995. Xce haplotypes show modified methylation in a region of the active $\mathrm{X}$ chromosome lying 3' to Xist. Proc. Natl. Acad. Sci. 92: 3531.

Dekker J., Rippe K., Dekker M., and Kleckner N. 2002. Capturing chromosome conformation. Science 295: 1306.

Duncan I.W. 2002. Transvection effects in Drosophila. Annu. Rev. Genet. 36: 521.

Duret L., Chureau C., Samain S., Weissenbach J., and Avner P. 2006. The Xist RNA gene evolved in eutherians by pseudogenization of a protein-coding gene. Science 312: 1653.

Goto T. and Monk M. 1998. Regulation of X-chromosome inactivation in development in mice and humans. Microbiol. Mol. Biol. Rev. 62: 362.

Hark A.T., Schoenherr C.J., Katz D.J., Ingram R.S., Levorse J.M., and Tilghman S.M. 2000. CTCF mediates methylationsensitive enhancer-blocking activity at the H19/Igf2 locus. Nature 405: 486.

Heard E. 2004. Recent advances in X-chromosome inactivation. Curr. Opin. Cell Biol. 16: 247.

2005. Delving into the diversity of facultative heterochromatin: The epigenetics of the inactive $\mathrm{X}$ chromosome. Curr. Opin. Genet. Dev. 15: 482.

Heard E., Mongelard F., Arnaud D., and Avner P. 1999. Xist yeast artificial chromosome transgenes function as X-inactivation centers only in multicopy arrays and not as single copies. Mol. Cell. Biol. 19: 3156.

Holmgren C., Kanduri C., Dell G., Ward A., Mukhopadhya R., Kanduri M., Lobanenkov V., and Ohlsson R. 2001. CpG methylation regulates the Igf2/H19 insulator. Curr. Biol. 11: 1128.

Huynh K.D. and Lee J.T. 2001. Imprinted X inactivation in eutherians: A model of gametic execution and zygotic relaxation. Curr. Opin. Cell Biol. 13: 690.

LaSalle J.M. and Lalande M. 1995. Domain organization of allelespecific replication within the GABRB3 gene cluster requires a biparental 15q11-13 contribution. Nat. Genet. 9: 386.

. 1996. Homologous association of oppositely imprinted chromosomal domains. Science 272: 725.

Lee J.T. 2000. Disruption of imprinted X inactivation by parentof-origin effects at Tsix. Cell 103: 17.

2002a. Homozygous Tsix mutant mice reveal a sexratio distortion and revert to random $\mathrm{X}$-inactivation. Nat. Genet. 32: 195.

. 2002b. Is X-chromosome inactivation a homology effect? Adv. Genet. 46: 25.

2005. Regulation of X-chromosome counting by Tsix and Xite sequences. Science 309: 768.

Lee J.T. and Lu N. 1999. Targeted mutagenesis of Tsix leads to nonrandom X inactivation. Cell 99: 47.

Lee J.T., Davidow L.S., and Warshawsky D. 1999a. Tsix, a gene antisense to Xist at the X-inactivation centre. Nat. Genet. 21: 400.

Lee J.T., Lu N., and Han Y. 1999b. Genetic analysis of the mouse $\mathrm{X}$ inactivation center defines an $80-\mathrm{kb}$ multifunction domain. Proc. Natl. Acad. Sci. 96: 3836.

Lee J.T., Strauss W.M., Dausman J.A., and Jaenisch R. 1996. A $450 \mathrm{~kb}$ transgene displays properties of the mammalian X-inactivation center. Cell 86: 83.

Lucchesi J.C., Kelly W.G., and Panning B. 2005. Chromatin remodeling in dosage compensation. Annu. Rev. Genet. 39: 615.

Luikenhuis S., Wutz A., and Jaenisch R. 2001. Antisense transcription through the Xist locus mediates Tsix function in embryonic stem cells. Mol. Cell. Biol. 21: 8512.

Lyon M.F. 1961. Gene action in the X-chromosome of the mouse (Mus musculus L.). Nature 190: 372.

. 1972. X-chromosome inactivation and developmental patterns in mammals. Biol. Rev. Camb. Philos. Soc. 47: 1.

Marahrens Y. 1999. X-inactivation by chromosomal pairing events. Genes Dev. 13: 2624.

Marahrens Y., Loring J., and Jaenisch R. 1998. Role of the Xist gene in $\mathrm{X}$ chromosome choosing. Cell 92: 657.

Marahrens Y., Panning B., Dausman J., Strauss W., and Jaenisch R. 1997. Xist-deficient mice are defective in dosage compensation but not spermatogenesis. Genes Dev. 11: 156 . 
McDonald L.E., Paterson C.A., and Kay G.F. 1998. Bisulfite genomic sequencing-derived methylation profile of the xist gene throughout early mouse development. Genomics 54: 379 .

Mlynarczyk-Evans S., Royce-Tolland M., Alexander M.K., Andersen A.A., Kalantry S., Gribnau J., and Panning B. 2006. $\mathrm{X}$ chromosomes alternate between two states prior to random X-inactivation. PLoS Biol. 4: e159.

Morey C., Arnaud D., Avner P., and Clerc P. 2001. Tsix-mediated repression of Xist accumulation is not sufficient for normal random X inactivation. Hum. Mol. Genet. 10: 1403.

Morey C., Navarro P., Debrand E., Avner P., Rougeulle C., and Clerc P. 2004. The region $3^{\prime}$ to Xist mediates X chromosome counting and $\mathrm{H} 3$ Lys-4 dimethylation within the Xist gene. EMBO J. 23: 594

Navarro P., Pichard S., Ciaudo C., Avner P., and Rougeulle C. 2005. Tsix transcription across the Xist gene alters chromatin conformation without affecting Xist transcription: Implications for X-chromosome inactivation. Genes Dev. 19: 1474.

Norris D.P., Patel D., Kay G.F., Penny G.D., Brockdorff N., Sheardown S.A., and Rastan S. 1994. Evidence that random and imprinted Xist expression is controlled by preemptive methylation. Cell 77: 41.

Ogawa Y. and Lee J.T. 2003. Xite, X-inactivation intergenic transcription elements that regulate the probability of choice. Mol. Cell 11: 731

Panning B., Dausman J., and Jaenisch R. 1997. X chromosome inactivation is mediated by Xist RNA stabilization. Cell 90: 907.

Penny G.D., Kay G.F., Sheardown S.A., Rastan S., and Brockdorff N. 1996. Requirement for Xist in X chromosome inactivation. Nature 379: 131.

Plath K., Mlynarczyk-Evans S., Nusinow D.A., and Panning B. 2002. Xist RNA and the mechanism of $X$ chromosome inactivation. Annu. Rev. Genet. 36: 233.

Prissette M., El-Maarri O., Arnaud D., Walter J., and Avner P. 2001. Methylation profiles of DXPas34 during the onset of X-inactivation. Hum. Mol. Genet. 10: 31.

Rastan S. 1983. Non-random X-chromosome inactivation in mouse X-autosome translocation embryos-Location of the inactivation centre. J. Embryol. Exp. Morphol. 78: 1.

Sado T., Hoki Y., and Sasaki H. 2005. Tsix silences Xist through modification of chromatin structure. Dev. Cell 9: 159

Sado T., Wang Z., Sasaki H., and Li E. 2001. Regulation of imprinted X-chromosome inactivation in mice by Tsix. Development 128: 1275

Stavropoulos N., Lu N., and Lee J.T. 2001. A functional role for Tsix transcription in blocking Xist RNA accumulation but not in X-chromosome choice. Proc. Natl. Acad. Sci. 98: 10232.

Stavropoulos N., Rowntree R.K., and Lee J.T. 2005. Identification of developmentally specific enhancers for Tsix in the regulation of $\mathrm{X}$ chromosome inactivation. Mol. Cell. Biol. 25: 2757.

Sun B.K., Deaton A.M., and Lee J.T. 2006. A transient heterochromatic state in Xist preempts $\mathrm{X}$ inactivation choice without RNA stabilization. Mol. Cell 21: 617.

Takagi N. and Sasaki M. 1975. Preferential inactivation of the paternally derived X-chromosome in the extraembryonic membranes of the mouse. Nature 256: 640.

Vazquez J., Muller M., Pirrotta V., and Sedat J.W. 2006. The Mcp element mediates stable long-range chromosomechromosome interactions in Drosophila. Mol. Biol. Cell 17: 2158 .

Vigneau S., Augui S., Navarro P., Avner P., and Clerc P. 2006. An essential role for the DXPas34 tandem repeat and Tsix transcription in the counting process of $\mathrm{X}$ chromosome inactivation. Proc. Natl. Acad. Sci. 103: 7390.

Wakimoto B.T. and Hearn M.G. 1990. The effects of chromosome rearrangements on the expression of heterochromatic genes in chromosome 2L of Drosophila melanogaster. Genetics 125: 141.

Willard H.F. and Carrel L. 2001. Making sense (and antisense) of the X inactivation center. Proc. Natl. Acad. Sci. 98: 10025.

Williams B.R. and Wu C.T. 2004. Does random X-inactivation in mammals reflect a random choice between two X chromosomes? Genetics 167: 1525.

Wu C.T. and Morris J.R. 1999. Transvection and other homology effects. Curr. Opin. Genet. Dev. 9: 237.

Xu N., Tsai C.L., and Lee J.T. 2006. Transient homologous chromosome pairing marks the onset of $\mathrm{X}$ inactivation. Science 311: 1149.

Yasuhara J.C. and Wakimoto B.T. 2006. Oxymoron no more: The expanding world of heterochromatic genes. Trends Genet. 22: 330.

Yoon B.J., Herman H., Sikora A., Smith L.T., Plass C., and Soloway P.D. 2002. Regulation of DNA methylation of Rasgrf1. Nat. Genet. 30: 92.

Yoon B., Herman H., Hu B., Park Y.J., Lindroth A., Bell A., West A.G., Chang Y., Stablewski A., Piel J.C., Loukinov D.I., Lobanenkov V.V., and Soloway P.D. 2005. Rasgrf1 imprinting is regulated by a CTCF-dependent methylationsensitive enhancer blocker. Mol. Cell. Biol. 25: 11184.

Zuccotti M. and Monk M. 1995. Methylation of the mouse Xist gene in sperm and eggs correlates with imprinted Xist expression and paternal X-inactivation. Nat. Genet. 9: 316. 


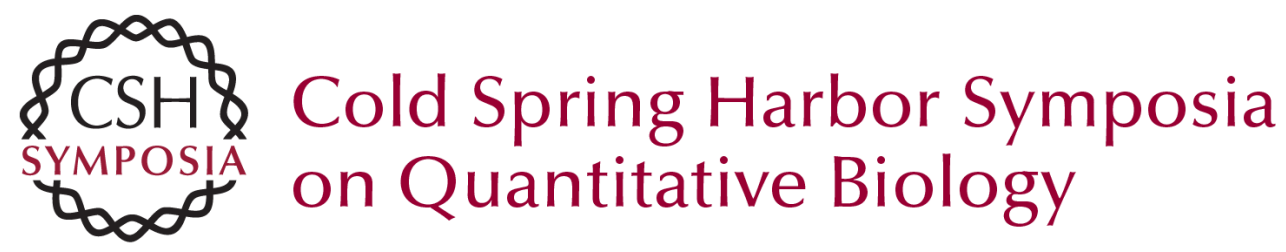

\section{X-Chromosome Kiss and Tell: How the Xs Go Their Separate Ways}

M.C. ANGUERA, B.K. SUN, N. XU, et al.

Cold Spring Harb Symp Quant Biol 2006 71: 429-437

Access the most recent version at doi:10.1101/sqb.2006.71.012

References This article cites 76 articles, 27 of which can be accessed free at: http://symposium.cshlp.org/content/71/429.full.html\#ref-list-1

License

Email Alerting Receive free email alerts when new articles cite this article - sign up in Service the box at the top right corner of the article or click here.

To subscribe to Cold Spring Harbor Symposia on Quantitative Biology go to: http://symposium.cshlp.org/subscriptions 